\title{
What Airbnb Can Teach Entrepreneurs About Layoffs
}

\author{
Tommaso Minola (University of Bergamo) \\ Mario Salerno \\ Daniel Agyare (University of Bergamo)
}

KEYWORDS: human resources, crisis management, COVID-19, Sharing Economy.

In May of 2020, Airbnb co-founder and CEO Brian Chesky sent a letter(https://news.airbnb.com/a-mes sage-from-co-founder-and-ceo-brian-chesky/) to all Airbnb employees around the world announcing the layoff of nearly 1,900 of the 7,500 employees (referred to as "teammates), or approximately $25 \%$ of its workforce.

The letter raised a number of debates and received much visibility. We feel the scrutiny and debate over it is important, mainly because it illustrates two "hard truths:"

(1) we don't know exactly when we will start traveling again; (2) when the trips return, they will look very different.

Chesky wrote frankly about the implications for Airbnb's business, including the need to go "back to the basics" of everyday people who want to provide hospitality, and to reduce investment in activities that don't support that focus. It also establishes the principles of consideration for those who will leave the company (attention and communication). It spells out Airbnb's measures for helping terminated employes -- liquidation plans, stock options, socio-health support and, above all, help in searching for the next job. It also urges managers to make careful, personal and timely communications to the people affected by these cuts.

We've had the chance to share the letter and discuss it with our networks of faculty colleagues, professionals, students and friends. We were stunned by the comments and questions that came up, and we are sharing them in this article. Our hope is to open up questions for discussion, to guide possible research efforts and to contibute to discussion in classrooms.

\section{What is surprising about the letter?}

Many studies suggest that workforce downsizing or layoffs should be considered as the "last resort." In fact,

\section{according to a recent Academy of Management Journal article,} (https://journals.aom.org/doi/10.5465/amj.2018.101 3) firms that are quick to downsize workforce in an economic downturn have, at least for two years after the event, poorer results in terms of stock performance than competitors who hold off on layoffs. This happens because when companies cut off a significant portion of their fixed costs - such as workforce - they lose "institutional memory" and find it difficult in hiring down the road; they also reduce employees' creativity, mostly because the latter become more risk-averse. In a study of more than 4,000 companies on the New York Stock Exchange over a 37-year period, from 1980-2016, researchers found that most employers see downsizing as quick fix for profitability and that companies that delayed downsizing employees fared better. This is possibly because they implemented other strategies first - also known as judicious precursors - such as temporary workforce redeployment, elimination of overtime, unpaid leave, voluntary retirement plans, hiring and salary freezes, operating at a temporal loss and most importantly, reducing incentive pay, particularly for highly compensated employees.

\section{A further significant factor is management} trustworthiness. This begins when employees recognize that transparency and most importantly, "shared sacrifice" are not just hollow corporate slogans. Trust comes when employees see management teams that make hard cost reduction choices before resorting to downsizing. This led, for example, to the success of Agilent and Xilinx, two outstanding high-tech firms that adopted such strategic approach during the "dotcom" bubble in the early 2000s. In their studies, Cascio and Wynn

(2004)

(https://onlinelibrary.wiley.com/doi/abs/10.1002/hr m.20034) describe how Agilent, before resorting to downsizing, froze hiring, implemented a three-month
Copyright ( 2020 The Authors. Entrepreneur \& Innovation Exchange is published at EIX.org. This is an open access article under the terms of the Creative Commons Attribution-NoDerivs License, which permits use and distribution in any medium, provided the original work is properly cited and no modifications or adaptations are made. View EIX.org Authorship Terms at https://eix.org/terms
FamilyBusiness 
$10 \%$ pay cut for senior managers, and eliminated management bonuses and travel/capital expense reductions. This "shared sacrifice" was widely acknowledged by its employees throughout the process and helped mitigate long-term impacts, including maximizing management's "psychological contract" with its workforce. We could not refrain from asking ourselves: was Brian Chesky aware of these challenges? What was unique about his decision and what is "different" with the Airbnb case, if at all?

\section{Why does this letter matter?}

Consider a giant like Airbnb, hailed as a prototype of an entrepreneurialfirm(http://leeds-faculty.colorado.e du/jere1232/Bromiley\%20and\%20Rau.pdf), aleader of the sharing economy, capable of being disruptive by challenging and redefining economic and regulatory barriers, and gaining market shares that are distant from one's own or have never existed before. Now imagine this giant being paralyzed by the ongoing economic situation at an unimaginable speed. Although Airbnb is a "unicorn

(https://familybusiness.org/content/Scholars-shoul d-study-everyday-entrepreneurs-not-

gazelles?search=unicorn) " (i.e. a company valued at more than a billion dollars), it operates in a cyclical industry and its fallout from Covid-19 is not surprising it's also affecting airlines, hotels, cruise ships, theme parks and other travel sectors. However, it is the manner in which the company executed and communicated its downsizing - which is quite unusual compared to similar companies in the tourism industry that captured large attention. Could this be due to Airbnb's status of an entrepreneurial firm that needs to grow and leverage on trust and perception of future growth prospects? Airbnb publicly announced the downsizing of its workforce by issuing an open letter that has been spread all over the world, compared to some of its counterparts (for example, Hilton), whose CEO only issued an internal communication to inform its employees about layoffs. Could it be that issuing an open letter about its downsizing reflects exactly how Airbnb wants to reveal its transparency towards stakeholders, shareholders and potential investors, thereby contributing to preserve the very value and growth prospects of the company?

\section{Time to re-consider the "unicorn" myth?}

Another important aspect is that this seems to challenge a particular idea about "innovation giants" like Airbnb: they do suffer, and sometimes even more than other firms, from shocks connected to the cyclical nature of the industry (or, better, the industries) in which they operate. Is the time right to consider a correction in the mythology about this type of firms?

In this vein, academic research (https://www.wsj.com/articles/six-theories-on-whyfast-growing-startups-seem-to-be-disappearing-11 588986419?fbclid=IwAR1gLnSyJRrnRUPoSI7IUm mLCa1RidT91IPvXTd7tHmoAgFG5zIRA3peAQw) has recently observed some signs of decline in the hightech start-ups phenomenon, or at least in the public praise of it. Out of the various reasons, we recall: a sort of return to "entrepreneurial lifestyle" businesses, without harsh concerns about exits with hyperbolic multiples; a number of regulatory threats in tech sectors; and some evidence of inadequate entrepreneurial training and skills to sustain high rate of growth-oriented businesses. Above all, questions seem to be increasing about the working conditions of the "gig economy," which isolates individuals and favors little networking and creativity among colleagues. These are typical factors behind many ventures (in fact, a large fraction of innovative ventures (https://link.springer.com/content/pdf/10.1007/s111 87-019-00189-y.pdf) have their gestation in organizations that "incubate" them). How many of these phenomena will be exacerbated by the pandemic emergency? Will entrepreneurial culture, especially the "garage culture," be able to find new ways?

\section{The ability to focus}

In many sectors, such as tourism, the current situation is truly an unprecedented and unthinkable shock. "This crisis has sharpened our focus to get back to our roots, back to the basics, back to what is truly special about Airbnb - everyday people who host their homes and offer experiences. (...) As I have learned these past eight weeks, a crisis brings you clarity about what is truly important," wrote Chesky. The Airbnb case offers somewhat unique perspective in its way of dealing with the crisis. We have heard many times, especially from 2008 onwards, that "crisis is an opportunity." But frankly, how many of us can clearly focus on a revision of priorities? How many are really doing it and are not limited to imitative acts of what others, individually or collectively, have done? And most importantly, how do you actually get the job done? 


\section{Managing people and human capital: a lesson from Airbnb?}

AirBed and Breakfast, now Airbnb, was established out of the desire to allow people to sleep on inflatable mattresses in other people's apartments around the United States for a few dollars. The founders relied on their brilliant intellect and determination to finance their first steps by selling personalized cereal boxes (the "Obama O's" and "Cap'n McCain's") during the 2008 US presidential campaign. This brilliant gambit earned Chesky \& Co. attention from a prominent US investor, who nonetheless missed the opportunity (https://avc.com/2011/03/airbnb/) to invest in the new company after it fell short of expectations ("We made the classic mistake that all investors make. We focused too much on what they were doing at the time and not enough on what they could do, would do, and did do. (...) The cereal box will remain in our conference room as a warning not to make that mistake again."). The value of human capital and talents must have been top of mind for Brian Chesky and his management team when facing the layoff decision and coping, in particular, with two main concerns.

Firsts, a corporation's downsizing or mass layoffs have a negative impact on the management's "psychological contract" with its remaining employees, damaging the psychological well-being of its workforce (survivor guilt

(https://www.sciencedirect.com/science/article/ab s/pii/S009026161730102X) ). This can lead to fear, confusion, lack of motivation and a decrease in productivity among employees, and can undermine a safe and welcoming working environment.

Second, several studies suggest that the most marketable (perhaps, the most experienced) staff members with alternative employment opportunities might be the first to leave during an economic downturn (as mentioned in the letter, the people who leave are not necessarily the least qualified; rather those who do not work in the areas on which the company intends not to focus in the near future). This may lead to a shortage of talented employees (adverse selection (https://www.shrm.org/hr-today/trends-and-forecas ting/special-reports-and-expertviews/Documents/Employment-Downsizing.pdf) ), one of the primary factors that hinder innovation.

In an effort to prevent the departure of best brains and maximally preserve management's "psychological contract," Chesky explains the action taken and the reasons for such action in a clear and comprehensive manner. He also makes it known to remaining employees that those who leave Airbnb are not abandoned to their fate. Finally, he stresses the organization's core values and how Airbnb aims to get back to its roots. Perhaps, that is how the CEO - in one way or the other - plans to mitigate the aforementioned issues, and presumably motivate or inspire those who remain in the company. To some extent, this sounds like starting the business all over again as the scenario is now completely different.

The letter being public is also a strong message to those who remain in the company for now, and in view of the long-lasting overall uncertainty. The storm might not be over and in any case, it is not yet clear how the tourism industry will reconfigure itself. Employees who remain in the company know that they are part of a project. It would seem obvious and, perhaps, heard a thousand times that people "are the center" of any business. Even so, the letter is still a striking, brilliant example of transforming an objectively negative situation into an opportunity for development.

To conclude, the letter emphasizes the manner in which the company treats its employees, as a way of doing business to create value in any circumstance. Could it be that one of the innovation giants of the past several years has, in the dawn of the crisis, shown us a way to innovate the way we lay off? We suspect this might be the case and we hope that the open questions collected in this article will ignite a vivid dialogue.

\section{Takeaways}

- When jolts occur, the courage to choose might take the form of a severe re-focus on the company "roots, back to the basics, back to what is truly special about [us]."

- Take a thorough look at your organization to decide whether layoffs are inevitable, and ponder on how and when you will communicate the news to your employees. Your message should be concise, clear and unequivocal.

- Plan for the unexpected but put the well-being of your employees and that of your productive assets above all else, by providing extended support and adequate assistance, in particular to the people you have laid off. Do not promise 
what you cannot deliver.

- Have a direct and open communication. It is important for your organization to have a wellstructured and standardized communication systems and procedures to ensure timely and transparent communication with all stakeholders.

- There will be profound concern and psychological distress among employees who survive the cut. Therefore, it is important to pick up the slack during this process, rebuild trust and restore confidence, while exploring ways to keep the morale of employees high. 